\title{
Geothermal gradient and heat flow data in and around Japan (I): Appraisal of heat flow from geothermal gradient data
}

\author{
Akiko Tanaka ${ }^{1}$, Makoto Yamano $^{2}$, Yusaku Yano ${ }^{1}$, and Masakatsu Sasada ${ }^{1}$ \\ ${ }^{1}$ Geological Survey of Japan, National Institute of Advanced Industrial Science and Technology, \\ AIST Tsukuba Central 7, 1-1-1 Higashi, Tsukuba, Ibaraki 305-8567, Japan \\ ${ }^{2}$ Earthquake Research Institute, University of Tokyo, Japan
}

(Received May 31, 2004; Revised October, 19, 2004; Accepted November 3, 2004)

\begin{abstract}
We published a CD-ROM "Geothermal Gradient and Heat Flow Data in and around Japan" (Tanaka et al., 2004a), which includes values of heat flow and geothermal gradient data. This compilation was intended to improve the understanding of variations in the thermal regime in and around Japan. Our current knowledge of the heat flow distribution can be increased by including information derived from geothermal gradient data contained in this compilation. In southern Kyushu, the pattern of heat flow is significantly modified by incorporation of estimates of heat flow from geothermal gradient data.
\end{abstract}

Key words: Heat flow, geothermal gradient, compilation, thermal regime, Japan.

\section{Introduction}

The thermal state of the lithosphere greatly influences tectonic and geological processes. For instance, it constrains the strength of the lithosphere, the modes of deformation, and the depth distribution of earthquakes. Therefore a comprehensive database of heat flow, thermal conductivity, and geothermal gradient is required to understand these processes and properties. Recently, we published a CD-ROM entitled "Geothermal Gradient and Heat Flow Data in and around Japan" (Tanaka et al., 2004a), which includes values of heat flow and geothermal gradient data. This information should be influenced by styles of crustal deformation and rheology, providing basic constraints on the topics addressed by "The Second International Symposium on Slip and Flow Processes in and below the Seismogenic Region”.

In this paper, we describe the contents of this CD-ROM, and add heat flow estimates derived from geothermal gradients to the database of heat flow in Japan. The heat flow pattern is significantly modified by incorporation of estimates of heat flow from geothermal gradient.

\section{Geothermal Gradient and Heat Flow Data in and around Japan}

"Geothermal Gradient and Heat Flow Data in and around Japan" has been published on CD-ROM (Compact DiskRead Only Memory). This CD-ROM contains current geothermal gradient and heat flow data in and around Japan. It provides data in two formats: Hypertext Markup Language (HTML) files and text files. An HTML file is a formatted file that can be read by a Web browser. A text file consists of tabular data that can be transferred into common

Copy right(c) The Society of Geomagnetism and Earth, Planetary and Space Sciences (SGEPSS); The Seismological Society of Japan; The Volcanological Society of Japan; The Geodetic Society of Japan; The Japanese Society for Planetary Sciences; TERRAPUB. software packages for data processing and analysis. A map is also available that shows distributions of data.

Yamano and his group collected the heat flow data in the northwestern Pacific area, from 0 to $60^{\circ} \mathrm{N}$ and from 120 to $160^{\circ} \mathrm{E}$ (Yamano, 1995). It consists of the following information: station name, coordinates, altitude (or water depth), number of temperature measurements, maximum measurement depth, temperature gradient, number of thermal conductivity measurements, average thermal conductivity, heat flow, reference and year of publication. The heat flow data provided in this CD-ROM is based on the above compilation (Yamano, 1995) and involves up-dated data as well as unpublished data, especially in poorly mapped region, such as the Korea Peninsula, East China Sea, and South China Sea. Additionally, denser measurements were made recently in specific regions, such as Nankai and Okinawa Troughs. As of 1992, the number of data reached about 2450 (Yamano, 1995), and our new compilation (Fig. 1(c)) contains 3184 values. This process is still ongoing, and the data will be updated on the internet.

The deep-sea areas of the northwestern Pacific are generally well covered in that new heat flow compilation. On land, however, heat flow data is relatively sparse. To fill the data gap, a new compilation of geothermal gradient data around Japan (Yano et al., 1999; Tanaka et al., 1999) was used (Fig. 1(a)). This compilation was to utilize extensive industry oriented thermal data sets, as well as the new research data. Although it has few temperature profiles, being mostly raw temperature-depth and geothermal gradient information and there is no evidence to evaluate the quality of measurements, geothermal gradient was estimated as follows: Geothermal gradient was calculated from the difference between the temperature at the bottom of each borehole or the maximum temperature in the borehole and the average surface temperature, which is estimated as the mean of annual average surface temperature during the 30 

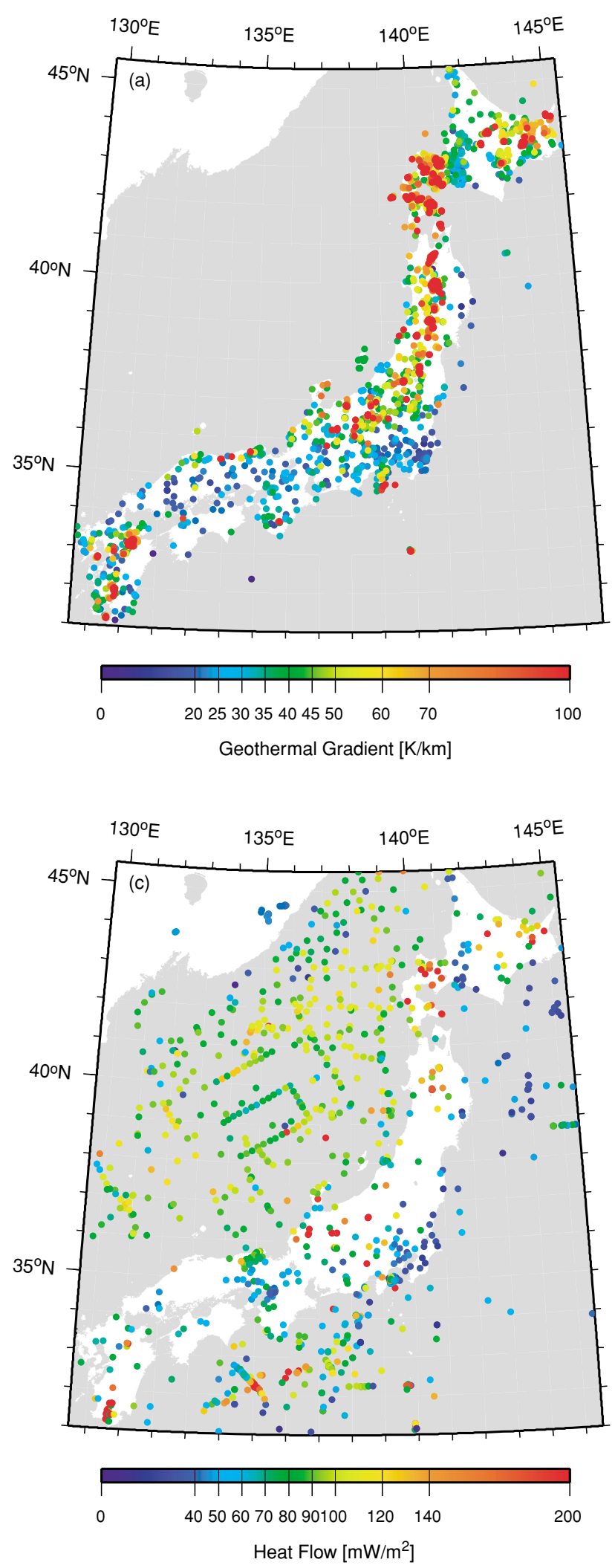
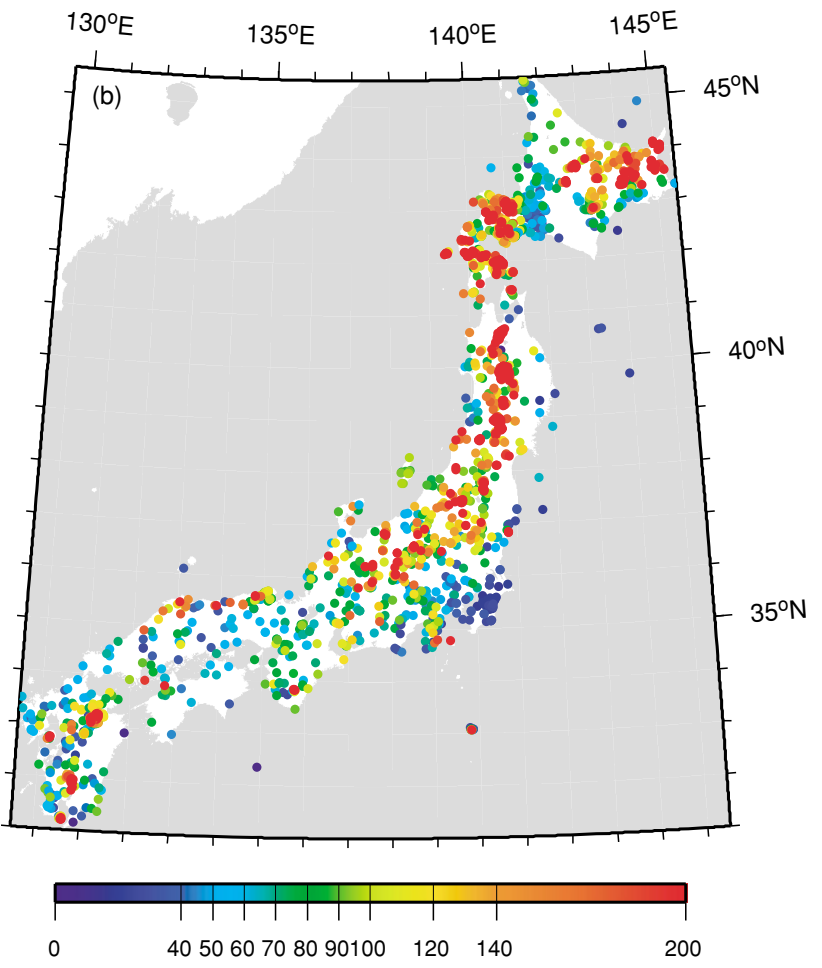

Heat Flow estimated from Geothermal Gradient $\left[\mathrm{mW} / \mathrm{m}^{2}\right]$

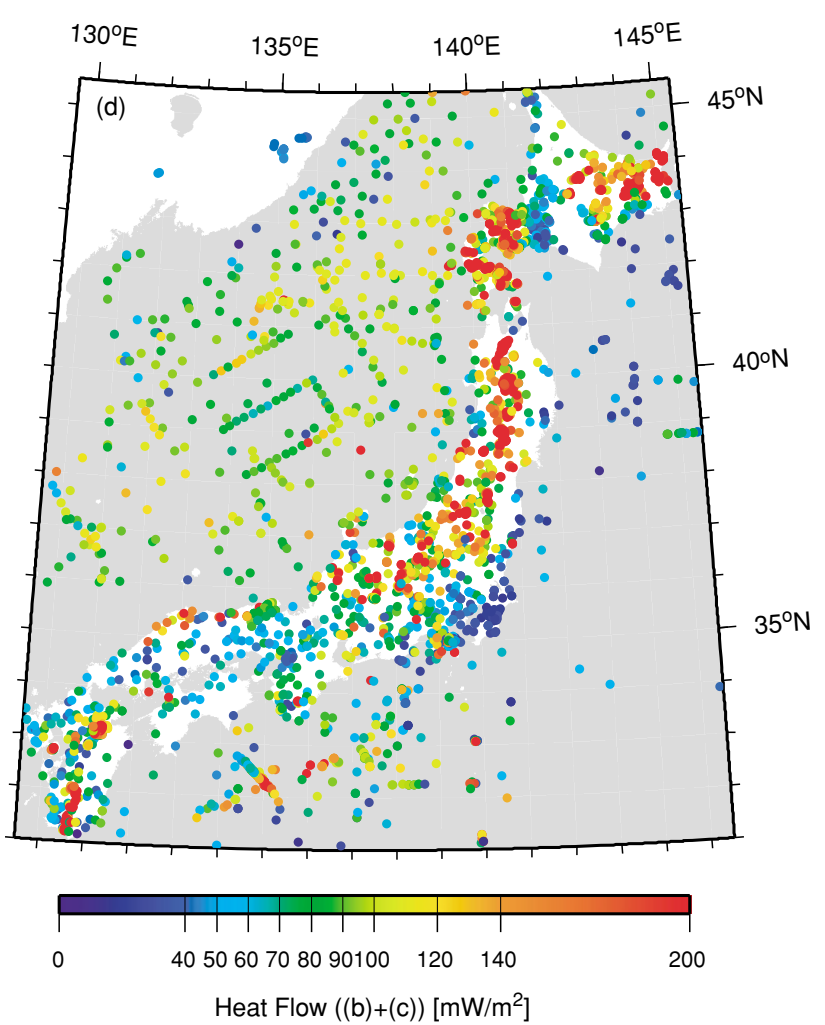

Fig. 1. The distribution of (a) geothermal gradient, (b) heat flow estimated from geothermal gradient, (c) observed heat flow, and (d) heat flow based on observed values including estimated values from geothermal gradient.

years from 1961 at the nearest meteorological station (National Astronomical Observatory, 1998). The data include longitude, latitude, geothermal gradient value, and borehole depth at 1937 sites. The number of geothermal gradient measurements is almost twice that of on-land heat flow data. There are many more geothermal gradients for shallow depths than deep, and the deeper the borehole, the better the quality in general. Because deeper borehole have less thermal disturbance, this compilation have used the borehole data of $300 \mathrm{~m}$ or more in depth, below the tran- 


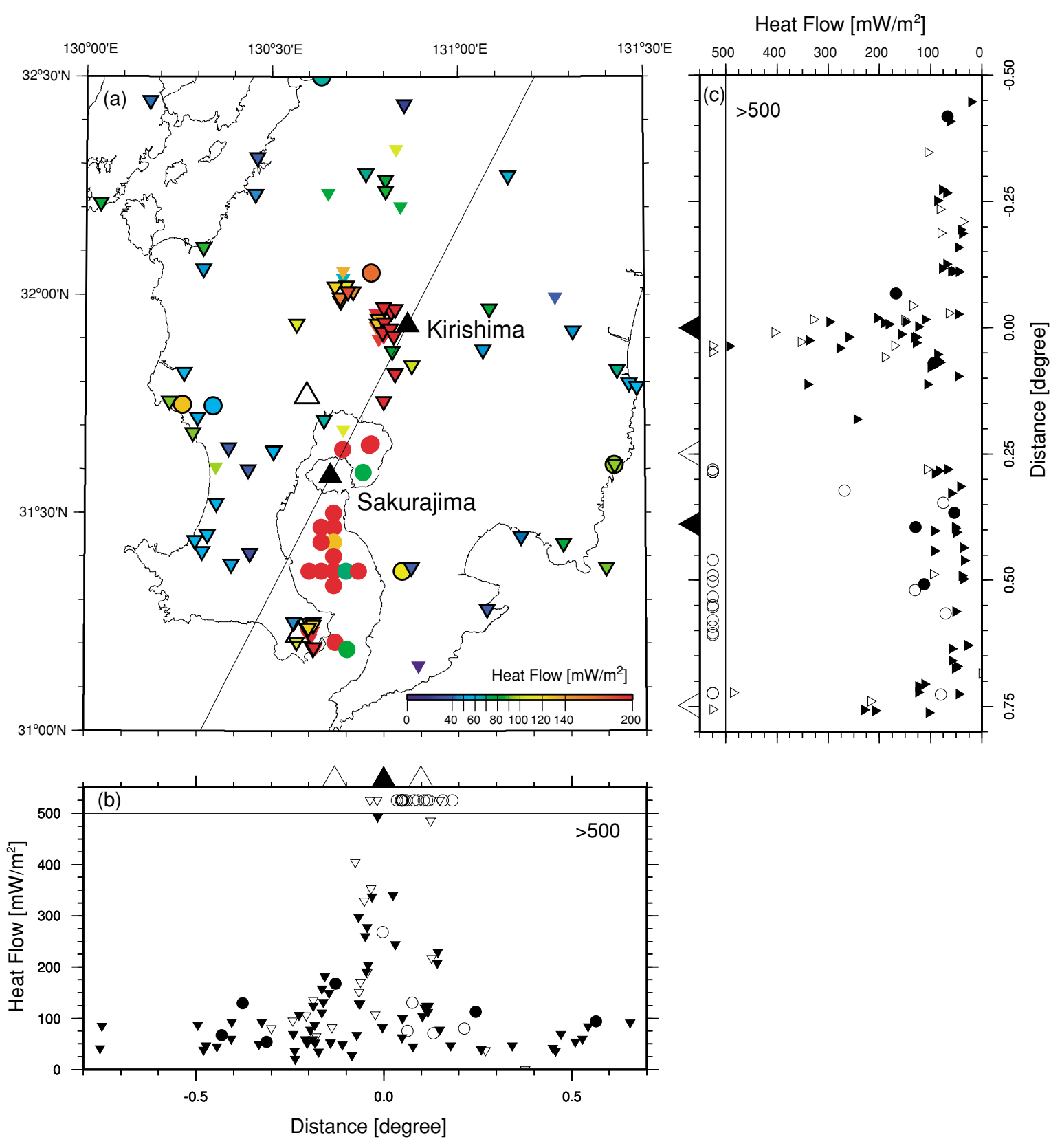

Fig. 2. (a) Heat flow distribution of southern Kyushu area. Circles and inverted triangles represent data from heat flow and estimated values from geothermal gradients. Outlined symbols correspond to high-quality data. Triangles show active volcanoes (Committee for Catalog of Quaternary Volcanoes in Japan, 1999). Solid triangles are ongoing and recent eruptions since 1996 (http://hakone.eri.u-tokyo.ac.jp/vrc/erup/erup.html). The solid line shows an active volcanic trend that extends from Kirishima volcanoes to Sakurajima volcano. (b) (c) Circles and inverted triangles represent data from heat flow and estimated values from geothermal gradients projected on vertical planes (b) perpendicular and (c) parallel to the active volcanic trend shown in (a). Solid and open symbols represent high-quality and low-quality data, respectively. The origin of the projection is placed at Kirishima Volcanoes.

sient effects of surface temperature variations and below the groundwater infiltration zone. Geothermal gradient measurement are more numerous and more widely distributed than heat flow measurement. Hence, it may be possible to estimate more detailed shallow thermal structure using thermal gradient data.

\section{Estimates of Heat Flow from Geothermal Gra- dient}

Near-surface heat-flow measurements provide a direct means to estimate the crustal thermal structure. Heat flow is determined by multiplying the geothermal gradient data by the thermal conductivity. Unfortunately, geothermal observations are made without thermal conductivity measurements. Therefore to estimate the heat flow using geothermal gradient data, the closest thermal conductivity data, which is included in our new compilation of heat flow data (Tanaka et al., 2004), is used for each gradient data. Then, the heat flow is estimated by multiplying each geothermal gradient data and its closest thermal conductivity. The median distance between the geothermal gradient data and the closest conductivity measurement is about $3 \mathrm{~km}$ and this approach does not take into account geological and hydrodynamical models to use the thermal conductivity, but this assumption 
works well enough to provide rough estimates of heat flow from geothermal gradient as shown in Fig. 1(b). Figure 1(d) show the combined heat flow distribution from measured (Fig. 1(c)) and estimated heat flow (Fig. 1(b)). The general features of the heat flow pattern are clearly visible. The regions with anomalously high heat flow generally coincide with volcanic and geothermal areas.

To show the improvement of the heat flow distribution by including geothermal gradient data, southern Kyushu area is presented as an example. In southern Kyushu, an area of extraordinarily high heat flow occurs near the southern end of the Japan Arc and is associated with active volcanoes. Figure 2(a) illustrates the possible distribution of heat flow in southern Kyushu. In this figure, the solid line shows the projection path, which connects Kirishima volcanoes and Sakurajima volcano. Figure 2(c) and (b) show the projected heat flow data along and perpendicular to the solid line shown in Fig. 2(a). Circles and inverted triangles are heat flow data from measurements and estimates using geothermal gradient, respectively. Outlined symbols in Fig. 2(a) or open symbols in Figs. 2(b) and (c) show the high-quality data, which explained later.

The quality and reliability of heat flow data varies widely. Its reliability depends on many factors, especially the procedures adopted for recording the data. It is required to check the original publications to know the data quality. Some data have no record of either thermal conductivity or number of measurements or altitude (or water depth). There are wide variations for reporting heat flow, so that the intrinsic quality of the data is difficult to evaluate. We assumed that the heat flow data accompanied with thermal conductivity data are of high quality. It is a rough assumption, but it may be enough for simple situation. In examining the quality of estimated heat flow from geothermal gradients, we have displayed the data for the "deep" borehole, $1000 \mathrm{me}$ ters and deeper, as outlined or solid symbols. It should be noted that data in relatively shallow boreholes might have been affected by the temperature disturbances. In general, the deeper the borehole, the better the quality geothermal gradient will be.

The measured heat flow data in this region is poorly mapped. Existing coverage of heat flow is too sparse to adequately resolve the crustal thermal structure. Combining the heat flow data with heat flow estimates from geothermal gradient data might be useful. The comparison of measured heat flow values with estimated values correlates qualitatively rather well with each other. To show the influence of volcanoes to crustal thermal regime, heat flow versus distance plot is shown in Fig. 2(b) and (c). These plots show how values of geothermal gradient and heat flow vary across and along the volcanic trend. Only poor-quality heat flow data, for which associated thermal conductivities were absent or the borehole is shallow, show values in excess of $500 \mathrm{~mW} / \mathrm{m}^{2}$, much higher than surrounding data. The heat flow decreases with increasing distance from the volcano as show in Fig. 2(b). The plot projected to a trend of active volcanoes (Fig. 2(c)), shows the regional variation of heat flow and its close correlation with active volcanoes.

\section{Discussions and Conclusion}

A database of "Geothermal Gradient and Heat Flow Data in and around Japan" is useful for modeling local and regional crustal thermal regime. New thermal data coupled with existing data help resolving horizontal heat flow gradients. Estimates of heat flow made by convolution of geothermal gradient data with thermal conductivities allow expansion of heat flow distribution.

Measurements of heat flow and geothermal gradient using boreholes on land are often concentrated in specific areas. By contrast, seismic stations of NIED Hi-net (National Research Institute for Earth Science and Disaster Prevention Hi-sensitive Seismograph Network), which is a newly established seismic network, are distributed almost homogeneously over the Japanese Islands with an average spacing of 20-30 km (http://www.hinet.bosai.go.jp/). Hinet consists of about 1000 borehole seismic stations with depths from 100 to $200 \mathrm{~m}$. Matsumoto (2002) measured thermal gradients and heat flow using NIED Hi-net boreholes. This data might be a valuable asset for improving the spatial resolution of heat flow distribution.

In this paper, we introduced a database of "Geothermal Gradient and Heat Flow Data in and around Japan" and its potential for estimating heat flow values from geothermal gradient data. In the following paper (Tanaka, 2004b), we will discuss how the lower cutoffs in seismicity vary with the thermal field.

Acknowledgments. The authors gratefully acknowledge helpful comments and suggestions from Dr. Montesi. All figures were prepared with Generic Mapping Tools developed by Wessel and Smith (1995).

\section{References}

Committee for Catalog of Quaternary Volcanoes in Japan (ed.), Catalog of Quaternary volcanoes in Japan, The Volcanological Society of Japan, 1999.

Matsumoto, T., Measurements of borehole thermal gradient on High Sensitivity Seismograph Network Japan (3), 2002 Japan Earth and Planetary Science Joint Meeting, J050-P001, 2002.

National Astronomical Observatory, Rika nenpyo (Chronological Scientific Tables), 1058 pp., 1998 (in Japanese).

Tanaka, A., Y. Yano, M. Sasada, Y. Okubo, K. Umeda, N. Nakatsuka, and F. Akita, Compilation of thermal gradient data in Japan on the basis of the temperatures in boreholes, Bull. Geol. Surv. Japan, 50, 457-487, 1999 (in Japanese with English abstract).

Tanaka, A., M. Yamano, Y. Yano, and M. Sasada, Geothermal Gradient and Heat Flow Data in and around Japan, Digital Geoscience Map DGM P5, Geological Survey of Japan, 2004a.

Tanaka, A., Geothermal gradient and heat flow data in and around Japan (II): Crustal thermal structure and its relationship to seismogenic layer, Earth Planets Space, 56, this issue, 1197-1201, 2004b.

Wessel, P. and W. H. F. Smith, New version of the Generic Mapping Tools released, Eos Trans., AGU, 76(33), 329, 1995.

Yamano, M., Recent heat flow studies in and around Japan, in Terrestrial Heat Flow and Geothermal Energy in Asia, edited by M. L. Gupta and M. Yamano, pp. 173-201, A. A. Balkema, Rotterdam, 1995.

Yano, Y., A. Tanaka, M. Takahashi, Y. Okubo, M. Sasada, K. Umeda, and N. Nakatsuka, Geothermal gradient map of Japan, Geological Survey of Japan, 1999 (in Japanese with English abstract).

A. Tanaka (e-mail: akiko-tanaka@aist.go.jp), M. Yamano, Y. Yano, and M. Sasada 